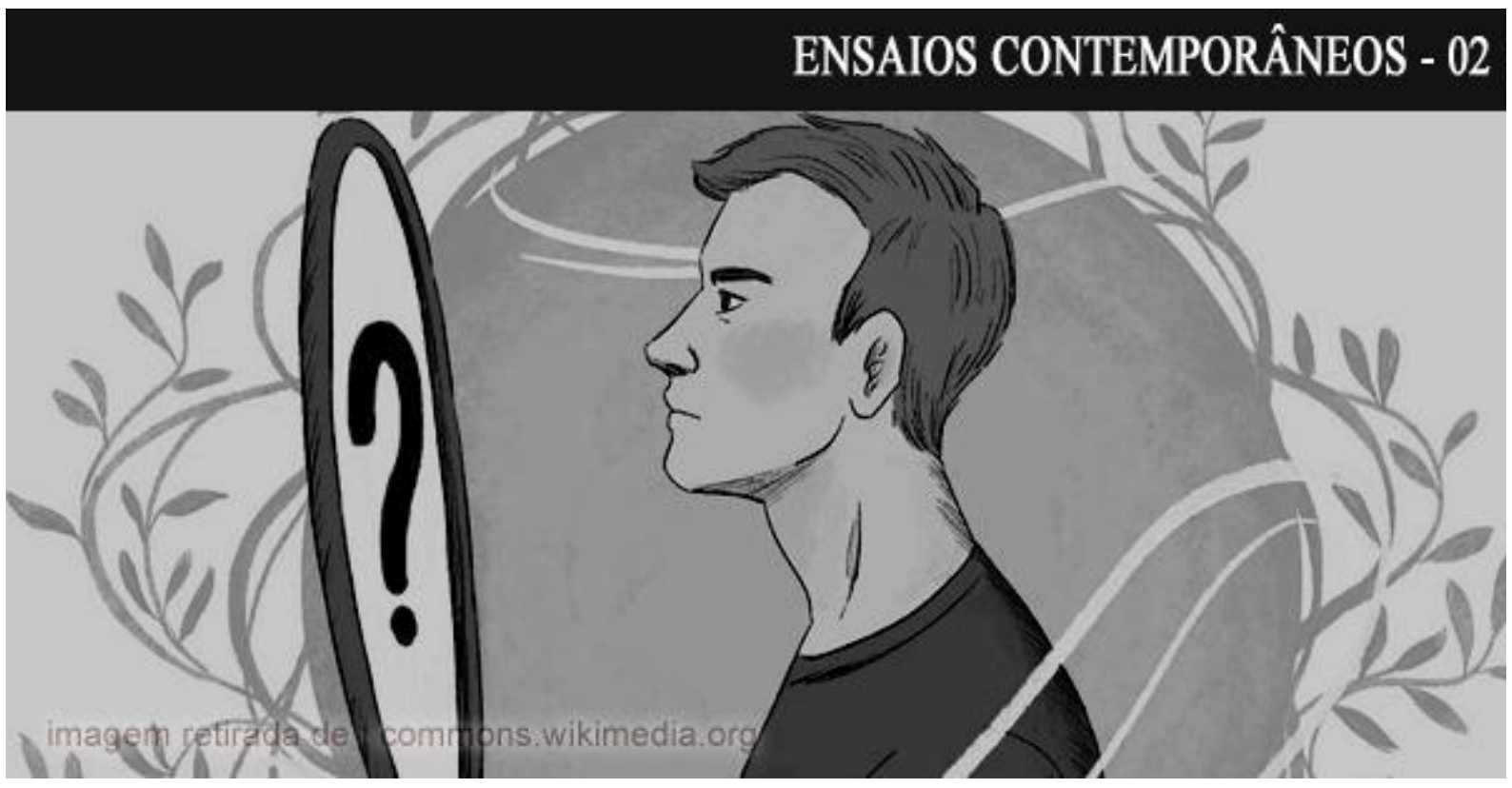

\title{
A CONSTRUÇÃO DA IDENTIDADE MASCULINA NA PÓS-MODERNIDADE: NOVAS PERSPECTIVAS A PARTIR DO FRALDÁRIO MASCULINO
}

\section{Estevão Trindade de Souza}

ORCID: https://orcid.org/0000-0001-5247-5225.

E-mail: estevaotsouza@gmail.com.

\section{Ligia Claudia Gomes de Souza}

ORCID: https://orcid.org/0000-0003-3326-6123.

E-mail: claudiapsisocial@gmail.com

Resumo: O presente trabalho busca compreender e discutir a forma como o homem cisgênero tem construído a sua identidade, na época atual, denominada pós-moderna. Para problematizar esse processo, a pesquisa utilizouse da lei de instalação de fraldários em banheiros masculinos, como meio de uma análise do contexto contemporâneo da formação identitária masculina e de novos modos de exercício da masculinidade, buscando, assim, mostrar um novo horizonte de possibilidades. O trabalho se articula teoricamente ao conceito de liquidez proposto por Zygmunt Bauman, destacando o conceito de sociedade líquida e o modo como ela influencia esse processo de construção da identidade masculina. Para tal fim, foi realizada uma revisão da literatura que apontou que há um processo de reformulação do conceito de masculinidade em curso e o fraldário no banheiro masculino indica a possibilidade de um novo exercício do masculino ao romper com a lógica machista e patriarcal.

Palavras-chave: Masculinidade. Identidade. Pós-modernidade. Bauman.

\section{THE CONSTRUCTION OF MASCULINITY IDENTITY IN THE POSTMODERNITY: NEW PERSPECTIVES FROM MASCULINITY BABY CHANGING STATION}

Abstract: This work aims to understand and discuss how the cisgender man lives his cultural identity in the present time, named as postmodern. To discuss this process, the research used the Brazilian law of installation of baby changing facilities in male bathrooms, as means to analyze the contemporary context of male identity formation and new ways of exercising masculinity, seeking a new horizon of possibilities for this process. Using as a theorical basis for this work, the "liquid society" concept, from "liquidity" concept by Zygmunt Bauman, is used to explain how it influences the construction process of male identity. In order to do this, a literature review was carried out. This indicated that there is an ongoing process of reviewing the concept of masculinity and the baby changing

\section{POLÊM!CA $\mid$ LABORÉ}

Polêmica - Revista Eletrônica da Uerj - Rua São Francisco Xavier, 524, $1^{\circ}$ andar bloco D, sl.1001 • Tels.: +55 21 2334-4088 / 4087 • http://www.e-publicacoes.uerj.br/index.php/polemica/index http://www.labore.uerj.br • laboreuerj@yahoo.com.br 
room in the men's bathroom, by breaking with sexist and patriarchal logic, suggests the possibility of a new male ways of living.

Keywords: Masculinity. Identity. Postmodernity. Bauman.

\section{Introdução}

A construção da identidade humana é um processo contínuo, que não cessa, pois é um tema mergulhado na subjetividade individual e influenciado pela intersubjetividade construída nas relações. Pensar em tal elaboração leva à análise de diversos fatores, entre eles: cultura, espaço-tempo, meio social etc. Por isso, é relevante o contexto que envolve o sujeito.

A época atual é compreendida de diversas formas e, neste trabalho, será tratada como pós-modernidade, um conceito utilizado para se referir ao período que marca o fim da modernidade e que traz com ele novos modos de construção subjetiva. Este tempo traz consigo uma característica peculiar, que é a dúvida acerca das certezas que a era moderna trazia sobre o homem, uma vez que, hoje, convivemos com a possibilidade de refletir e produzir novos jogos identitários. Muitas verdades tidas como respostas para as questões humanas ou normatizadoras das relações sociais são colocadas à prova e já não são aceitas sem questionamentos.

Uma dessas verdades questionadas, posteriormente, se desdobrou em uma discussão que abrange toda a sociedade atual, ou seja, o significado de ser homem e seu lugar na sociedade. Até então, considerava-se o homem em uma perspectiva patriarcal, em uma posição dominante, que emanava respeito e subordinação. Havia, inclusive, pensamentos que se respaldavam na biologia como uma forma de garantir essa hegemonia.

A partir da divisão social dos papéis de gênero, estabeleceram-se algumas diferenças entre os papéis de homem e de mulher, definindo, por conseguinte, o conceito do que é ser homem. Por gênero, entende-se que é a forma cultural de entender e distinguir o papel do homem e da mulher. É uma construção social sobre o que é adequado a cada um dos sexos e como eles se relacionam, mas diferencia-se de sexo justamente aí, na medida em que este pode divergir da identidade de gênero. Cabe ressaltar que, neste trabalho, a primeira análise recai sobre o homem cisgênero.

Os movimentos feministas, ao reivindicarem o lugar da mulher na sociedade, propiciaram essa discussão sobre a masculinidade e os efeitos de sua construção simbólica sobre a sociedade, abordando sua falsa superioridade sobre a mulher. Foi preciso questionar essa posição suprema do homem para então se chegar ao debate sobre a mulher, seu papel e suas limitações impostas por uma cultura datada. Tais discussões geraram o que se entende

\section{POLÊM!CA $\mid$ LABORẸ}

Polêmica - Revista Eletrônica da Uerj - Rua São Francisco Xavier, 524, $1^{\circ}$ andar

bloco D, sl.1001 • Tels.: +55 21 2334-4088 / 4087 • http://www.e-publicacoes.uerj.br/index.php/polemica/index

http://www.labore.uerj.br • laboreuerj@yahoo.com.br 
como uma crise na masculinidade, levando os homens a repensarem toda a sua trajetória e o modo como se estabelecem enquanto homens.

Esse cenário favoreceu o surgimento de um novo questionamento, que norteará este trabalho: como é ser homem na pós-modernidade? Com base nas proposições do sociólogo polonês Zygmunt Bauman (1998, 2001, 2013), ao postular sobre a liquidez que permeia toda a era pós-moderna, acredita-se que a estes homens caiba a adaptação ao pensamento pósmoderno, com a abertura de novas possibilidades para o ser independente da dicotomia de papeis anteriormente imposta por gênero.

Até a Modernidade, ao homem cabia seguir os preceitos hegemônicos, ditados por uma sociedade heteronormativa, pois do contrário estariam sujeitos a serem julgados e subalternizados. Porém, com a atual quebra de paradigmas, o homem passa a ter liberdade para fazer suas escolhas baseadas em sua subjetividade, não mais precisando se reprimir para que, desta forma, se adeque aos padrões impostos.

Uma das possibilidades de quebra dessa lógica se evidencia na criação do fraldário masculino. Este se configura como um elemento muito importante, que funciona como uma política afirmativa de que também cabe ao homem o exercício do cuidado e amparo a uma criança - um claro exemplo de algo que historicamente foi definido como função feminina. Analisaremos tal peça de forma a mostrar a sua importância e significado, nesse momento de mudança, e o seu papel no desenvolvimento de novas masculinidades.

O objetivo desse ensaio teórico foi rever os pontos de vista teóricos de autores sobre a questão da identidade masculina na pós-modernidade e problematizar a construção desse processo tão complexo. Ao pensar o fraldário masculino, partimos do pressuposto da abertura a novas possibilidades identitárias, característica da pós-modernidade, quando a fluidez e as transformações frequentes marcam o jogo relacional homem/sociedade. Esse debate se insere no campo de possibilidades identitárias que circundam o homem pós-moderno, contribuindo para a compreensão do processo de construção desses jogos identitários na contemporaneidade.

\section{Construções da masculinidade}

A sociedade brasileira vive, atualmente, um momento de discussão, desconstrução e reconstrução de diversos conceitos, dentre eles, o de masculinidade ou a identidade masculina, ambos imersos em um processo de construção sócio-histórica e cultural. Ao longo de épocas, foram atribuídos determinados papéis para o sujeito do sexo masculino, colocando-o em

\section{POLÊM!CA LABORE}

Polêmica - Revista Eletrônica da Uerj - Rua São Francisco Xavier, 524, $1^{\circ}$ andar

bloco D, sl.1001 • Tels.: +55 21 2334-4088 / 4087 • http://www.e-publicacoes.uerj.br/index.php/polemica/index http://www.labore.uerj.br • laboreuerj@yahoo.com.br 
posição de superioridade e de responsabilidade, tais como, "chefe da família", o "provedor do sustento da casa", o "protetor do lar".

Essas atribuições dadas ao homem, consequentemente, trouxeram indicações de comportamentos para as mulheres também. Diante disso, surgem os papéis sociais atribuídos a homens e a mulheres, corroborados pelo que defende Abreu (2013), ao postular que os homens trabalhavam fora de casa para prover o sustento e as mulheres se dedicavam exclusivamente à criação de seus filhos e às tarefas domésticas. Esse modelo se baseia na visão patriarcal e vai muito mais a fundo e se desdobra em comportamentos muito específicos para ambos.

Mas, a partir da revolução sexual da década de sessenta, do século XX, que trouxe consigo a luta das mulheres por sua emancipação e ocupação de outros espaços nos jogos sociais, surgem novos posicionamentos e, por conseguinte, novas formas de ser do feminino e do masculino. Com a entrada da mulher no mercado de trabalho, criam-se algumas lacunas que devem ser preenchidas. Nesse momento, as mulheres exigem que seus parceiros tomem uma nova posição concernente à dinâmica familiar e o homem, que até então apenas sustentava a casa, passa a ter novas funções, como, por exemplo, participar do processo educacional dos filhos.

Verdades não são absolutas e podem se transformar em outra coisa e não mais influenciar da mesma forma que outrora. De tal modo, a sociedade contemporânea, que ainda é influenciada pela separação de funções por sexo, tem uma nova possibilidade de subsistência.

Nessa divisão social e cultural, socialmente construída, estabeleceram-se papéis e limitaram-se conceitos de ambos os gêneros, apontando o que é adequado a cada um dos sexos e como eles se relacionam. Da figura masculina sempre foi esperado que fosse o provedor, protetor e o chefe da casa. O que significa dizer que sua esposa e filhos deveriam ser totalmente submissos a este homem - comportamento esperado e normatizado.

Além disso, por muito tempo, ser homem significava não ser feminino, não ser homossexual, não ser sentimental ou dócil, não manter relações muito próximas com outros homens e não ser impotente com as mulheres. Ainda hoje persistem esses padrões de masculinidade, mas há uma abertura social que vem quebrando as hegemonias do passado, produzindo padrões coexistentes em uma mesma sociedade e vislumbrando o caráter tóxico desse estereótipo.

A imposição masculina tradicional, inserida num campo de poder, culminou no termo amplamente utilizado "masculinidade hegemônica". Tal termo reflete bem a posição social em

\section{POLÊM!CA LABORÉ}

Polêmica - Revista Eletrônica da Uerj - Rua São Francisco Xavier, 524, $1^{\circ}$ andar bloco D, sl.1001 • Tels.: +55 21 2334-4088 / 4087 • http://www.e-publicacoes.uerj.br/index.php/polemica/index http://www.labore.uerj.br • laboreuerj@yahoo.com.br 
que fora colocado o homem, cuja superioridade advém do subjugamento das mulheres, consideradas inferiores.

Segundo Rabelo (2010), a cultura é a responsável pelas definições de gênero. É ela quem dita a construção da masculinidade e normatiza sentimentos e formas de comportamento, que, em suma, se dão no distanciamento de características daquele que se constitui como Outro. A cultura ocidental é predominantemente patriarcal e é dela que advém o padrão de masculinidade hegemônica.

Uma forma de tentar padronizar os papéis de gênero pode ser vista em lojas de brinquedos pela existência, por exemplo, de um setor de menino e outro de menina. Bonecas, produtos cor de rosa, brinquedos que simulam uma casa, são para as meninas, e para os meninos destinam-se carrinhos, skates, super-heróis e os produtos em maioria de cor escura.

O questionamento sobre a masculinidade foi influenciado pelas mulheres, no rastro do movimento feminista, que, ao reivindicar o seu lugar, mostrou a indefinição do que é ser homem. Nos fundamentos da sociedade patriarcal, compete ao homem desempenhar todo e qualquer papel que seja de importância para o corpo social, sendo a mulher diminuída e não considerada. Uma perspectiva enfrentada pelo feminismo, que lançou luz sobre as particularidades culturais que fortificavam as diferenças relatadas anteriormente.

Desde a tenra idade, os meninos são ensinados que atitudes e comportamentos femininos são inaceitáveis e que diminuem sua condição masculina. A frase 'homem não chora', por exemplo, corrobora tal ideia. Ao atingirem determinada idade e iniciarem a vida sexual, os rapazes são pressionados a serem conquistadores e quando não atingem esse status, têm sua masculinidade colocada em dúvida.

Eles crescem tendo seus sentimentos reprimidos e transferem para o pênis a responsabilidade e a confirmação de sua masculinidade. O homem não pode ser impotente, precisa ser o 'todo poderoso'. No contexto brasileiro, esse fato ainda se associa ao que Ericeira (2008) chama de complexo de latinidade: brasileiros e demais latinos são estereotipados como sexys e 'bons de cama', o que aumenta a responsabilidade no ato sexual.

É possível afirmar que a masculinidade é uma dívida que os próprios homens atribuíram aos seus pares, pois, culturalmente, ela se dá no que se espera ser feito e pensado. Esse é apenas um dos reflexos da dominação masculina que afeta a sociedade de forma tão abrangente, em que até a linguagem sofre tal influência. Um exemplo claro dessa situação é num grupo de pessoas em que há apenas um homem e várias mulheres, e usa-se o pronome 'eles', de forma a

\section{POLÊM!CA LABORE}

Polêmica - Revista Eletrônica da Uerj - Rua São Francisco Xavier, 524, $1^{\circ}$ andar bloco D, sl.1001 • Tels.: +55 21 2334-4088 / 4087 • http://www.e-publicacoes.uerj.br/index.php/polemica/index http://www.labore.uerj.br • laboreuerj@yahoo.com.br 
incluir esse homem no contexto da fala, sendo que o contrário não acontece.

Essa construção sob moldes patriarcais sempre representou um peso muito grande sobre o menino/homem, produzindo uma angústia severa naqueles que precisavam reprimir os seus verdadeiros eus, já que tinham que se encaixar dentro do padrão para serem aceitos na sociedade.

Sobre a influência do patriarcado, Ericeira (2008, p. 7) defende que "os homens contemporâneos estariam em crise, pois não se coadunariam mais com os moldes do passado patriarcal". Esta crise pode ser vista como resultado do movimento feminista, uma vez que, a partir dele, surgiram as discussões sobre essa questão. Porém, as regras sobre a masculinidade estão intrínsecas à sociedade e sua reprodução tem sido automática, o que gera desconforto no momento em que são questionadas e repensadas.

O significado de ser homem hoje já não é mais o mesmo de há dez anos. As regras e as leis morais que sempre regeram a sociedade têm passado por mudanças, sendo assim, comportamentos inaceitáveis há uma década, no presente, caminham para serem tidos como normais - do mesmo modo o inverso ocorre. Essas mudanças influenciam diretamente os homens, pois eles percebem agora uma liberdade de serem quem realmente são, desvinculandose de padrões impostos.

A partir dessa reflexão inicial, pode-se concluir que não há apenas uma identidade masculina e sim identidades masculinas. Desta forma, surge o debate sobre as diferentes masculinidades somado à crescente ascensão da mulher e, decorrente disso, a ressignificação do lugar do homem, que marca a crise pela qual passam.

A pós-modernidade é marcada por transformações que ocorrem em todos os âmbitos da sociedade e é cenário no qual se dá tal crise. Nela surgem novas maneiras de pensar, ser e agir. Para Bonácio (2012, p. 233), a era pós-moderna está “[...] configurando novas maneiras de pensar a sociedade, assim como uma nova forma de cultura e pensamento, o que vem levando ao declínio os valores e as grandes instituições clássicas". A autora complementa que o ser humano possui uma liberdade atualmente que gera uma divisão no sujeito entre a adequação social e o medo de não seguir junto com as mudanças.

No processo de construção da identidade de um sujeito é preciso considerar, ainda, a mídia. Ela tem o poder de alcançar diversas pessoas nos mais diferentes locais do mundo, possibilitando, assim, uma idealização do que seja o caminho certo a seguir. Por meio dela, é possível criar um referencial, um padrão, demonstrando sua importância como ferramenta no

\section{POLÊM!CA $\mid$ LABORE}

Polêmica - Revista Eletrônica da Uerj - Rua São Francisco Xavier, 524, $1^{\circ}$ andar bloco D, sl.1001 • Tels.: +55 21 2334-4088 / 4087 • http://www.e-publicacoes.uerj.br/index.php/polemica/index http://www.labore.uerj.br • laboreuerj@yahoo.com.br 
processo de formação dessa identidade, seja de forma positiva ou negativa.

Os meios de difusão de informação têm uma grande responsabilidade sobre a crise na qual o homem pós-moderno se encontra. As “[...] práticas discursivas identitárias [...]" propagadas pelas “[...] lentes da mídia [...]” levam à construção de uma nova imagem da figura masculina, desconstruindo a imagem do homem tradicional, provedor e, também machista (BONÁCIO, 2012, p. 239). Machado (2016) aponta que a quebra do padrão dos comportamentos tidos como masculinos é o que permite o entendimento do que é a crise masculina. É fato que há uma instabilidade no que tange à identidade masculina, porém, isso não significa dizer que está surgindo um novo modelo de homem, mas sim outros homens.

Conforme Botton (2007), o suposto saber brasileiro define o homem pela atividade ou passividade dentro da relação sexual, colocando desta forma como sendo um legítimo homem aquele que penetra. Esta penetração independe de que corpo seja, ainda que de outro homem nesse cenário a masculinidade desse sujeito não será afetada -, enquanto se o homem for penetrado, este perde seu status viril.

Dentro do conceito de masculinidade hegemônica, uma separação sempre foi um tema central: a separação, a exclusão e a subordinação do homossexual. Sempre houve um policiamento da heterossexualidade, para que, assim, nenhum homem fugisse dos padrões estabelecidos para o sexo masculino. Um padrão em que homem é dominador/ativo e que todo aquele que não se encaixe nisso deva ser dominado/passivo.

Muito se discute sobre a homossexualidade, homofobia e afins, sendo que este debate não é sobre uma nova forma de ser e sim de aceitação e afirmação de algo já existente, implicando em princípios básicos das relações humanas, tais como respeito e tolerância. Essas características são avessas ao sistema patriarcal, culminando na problemática atual de enfrentamento e ódio.

Mesmo em meio a esse cenário de desequilíbrio e instabilidade, o homem homossexual tem um importante papel para a desconstrução dos conceitos hegemônicos. A homossexualidade masculina mostra outra possibilidade de ser homem, sem seguir os padrões impostos ao longo do tempo. O sujeito homoafetivo pode apresentar características que são totalmente contrárias ao conceito estabelecido e imposto do que é ser homem, incluindo as ditas "afeminadas".

As recentes desconstruções incômodas para o homem contrapõem, de um lado, o patriarcado ainda ditando as regras de "como ser macho" e, do outro, a evolução da sociedade

\section{POLÊM!CA LABORÉ}

Polêmica - Revista Eletrônica da Uerj - Rua São Francisco Xavier, 524, $1^{\circ}$ andar

bloco D, sl.1001 • Tels.: +55 21 2334-4088 / 4087 • http://www.e-publicacoes.uerj.br/index.php/polemica/index http://www.labore.uerj.br • laboreuerj@yahoo.com.br 
como um todo, que entende que as tais características dicotômicas independem de gênero.

Porém, a crise pela qual passam os homens é mais ampla e não se limita às características pessoais. $\mathrm{O}$ fato de a mulher alcançar espaços e posições até então exclusivos do homem abalou seu conceito de dominação. O poder masculino, creditado a uma determinação biológica no passado, agora é visto como uma construção histórica. E se foi construído, pode ser desconstruído.

O conceito da masculinidade hegemônica está tão enraizado que tudo que diverge dele causa estranhamento. Por mais desconstruído que um sujeito possa ser, em algum momento, ele se depara com pensamentos, atitudes e conceitos advindos do patriarcado. O homem se encontra com uma angústia da qual não consegue ser capaz de elaborar se não repensar a sua subjetividade.

Ao evocar as memórias discursivas, há a representação do homem forte e que não demonstra sentimentos e inseguranças, uma vez que tais demonstrações seriam exclusivas das mulheres. É possível afirmar que isso contribuiu para a tipificação da mulher como o "sexo frágil”, como ilustra Bonácio (2012), devido a suposta ideia de que a mulher era quem se deixava levar pela emoção, enquanto o homem detinha a razão. A mídia hodiernamente veicula um novo imaginário que propicia um deslocamento de tais atributos. $\mathrm{O}$ homem agora pode ser sentimental, sem precisar ser violento ou demonstrar força para ser aceito.

Entende-se, portanto, que esta é uma construção histórica, e não biológica, visto que demonstrar emoções, perder certo status hierárquico ou ser sensível são conjunturas que não se relacionam com ser ou não ser forte. $\mathrm{O}$ "sexo forte", racional e seguro vinculado à identidade masculina passou a demonstrar sentimentos, apreensões, se encaixando no "sexo frágil", e até misturando ambos. Com esse deslocamento e a pluralidade da identidade de gênero presente, um sujeito angustiado pode emergir.

O homem sempre foi ensinado a ter determinadas obrigações e exercer funções préestabelecidas, pois tais eram inerentes ao seu sexo. Esse tipo de pensamento era, e ainda é corroborado por frases do tipo: "homem de verdade", "homem de natureza", "homem que é homem”, entre outras. Ao se reproduzir tais afirmações, reforça-se a ideia de que só existe uma forma de ser homem, porém, conforme Ericeira (2008) reforça, não se pode falar em identidade masculina e sim em identidades masculinas, pois a pluralidade de opiniões e de existências não permite uma uniformização.

Um exemplo de tal diversidade é elucidado por Lago e Wolff (2013), que explicam a

\section{POLÊM!CA $\mid$ LABORÉ}

Polêmica - Revista Eletrônica da Uerj - Rua São Francisco Xavier, 524, $1^{\circ}$ andar

bloco D, sl.1001 • Tels.: +55 21 2334-4088 / 4087 • http://www.e-publicacoes.uerj.br/index.php/polemica/index

http://www.labore.uerj.br • laboreuerj@yahoo.com.br 
masculinidade homossexual como um contraponto e um antiparadigma da masculinidade hegemônica. Vale citar que, para Machado (2016), a hegemonia não é tão corriqueira como imaginado, pois uma minoria dos homens a adota. Contudo, o conceito hegemônico é sim normativo.

O heterossexismo, a homofobia, a dominação masculina e a subordinação da mulher ao homem são pontos inerentes à definição de masculinidade hegemônica. Por isso, é destacada a importância do homem gay para essa desconstrução, já que a sua masculinidade, que vai de encontro à hegemonia, vem legitimar e abrir espaço para que outras formas de ser homem sejam aceitas e consideradas pela sociedade em geral.

A aspiração de ser aceito socialmente e de se sentir pertencente a algo são características do ser humano e, quando isso não ocorre, tal rejeição pode ser fonte de muita angústia e sofrimento. Em prol de serem benquistos, muitos homens durante um bom tempo sofreram psiquicamente por não poderem exprimir suas verdadeiras identidades. Entretanto, com as quebras de paradigmas sobre a masculinidade, observa-se que cada vez mais homens têm assumido suas verdadeiras identidades ao perceberem que agora há espaço para os tidos como diferentes. Dentre esses se encaixam todos aqueles que outrora foram discriminados por terem determinadas características que não se coadunavam com o modelo tradicional, como o homem homossexual.

Para além disso, há ainda a reformulação da compreensão de gênero. De acordo com Siqueira (1997), a formação da identidade de gênero do sujeito é construída a partir das significações vividas ao longo do tempo. A família de origem, a classe social, a sociedade, o tempo, a relação com os pais, irmãos e demais familiares são fatores que marcam e deles derivam significados sobre masculino e feminino. A autora destaca que não se sucede uma simples reprodução de atitudes, mas uma adequação de toda essa rede de significância, estabelecendo assim os seus próprios significados. Ainda segundo a autora, "as ações dos outros não estabelecem determinantemente as ações e os conhecimentos do sujeito, mas são constitutivas deste" (SIQUEIRA, 1997, p. 6). Tais pensamentos mostram que essa construção da identidade individual é baseada nas suas relações e nos significados que se atribui a elas.

O homem adulto de hoje cresceu e se constituiu a partir das suas relações, as quais, em muitos casos, eram regidas pelo pensamento patriarcal, o que possibilitava a manutenção da hegemonia masculina. Isto incita o indivíduo a continuar reproduzindo as práticas e pensamentos tradicionais referentes ao que se esperava do gênero masculino.

\section{POLÊM!CA LABORÉ}

Polêmica - Revista Eletrônica da Uerj - Rua São Francisco Xavier, 524, $1^{\circ}$ andar bloco D, sl.1001 • Tels.: +55 21 2334-4088 / 4087 • http://www.e-publicacoes.uerj.br/index.php/polemica/index http://www.labore.uerj.br • laboreuerj@yahoo.com.br 
Com os questionamentos dos movimentos feministas sobre a masculinidade hegemônica, as bases identitárias se abalaram. Entretanto, tal crise possibilitou que tantos quantos não se encaixavam nos moldes tradicionais pudessem ser também reconhecidos e entendidos como homens.

Ao longo das últimas décadas, as pessoas modificaram seu modo de se relacionar. No que tange o homem e a mulher, masculino e feminino, ocorreu uma desconstrução de pensamentos, na qual se busca uma igualdade em que se respeite as particularidades de cada gênero - e ainda seu descolamento ao sexo biológico. Existe uma discussão vigente em volta desse tema e isso afeta diretamente cada sujeito, pois conforme vão alterando-se os pensamentos, as relações também se alteram, sendo que estas fazem parte da construção da identidade de cada um (SIQUEIRA, 1997).

\section{A sociedade líquida}

Com a pós-modernidade surgem novas formas de fazer ciência, arte, de pensar e se comunicar. Isso resulta numa nova maneira de conceber a sociedade e de constituir a cultura, o que leva ao entendimento de que a sociedade como um todo passa por um processo de transição de identidade.

Para Bonácio (2012), a cultura pós-moderna alterou tudo e todos, inclusive levando a um enfraquecimento dos valores e das grandes instituições. Passou-se a compreensão de que nada mais possui o caráter de verdade absoluta, já que tudo seria passível de questionamento e dúvida. Ao pensarmos na masculinidade, vemos o quão esse conceito é influenciado por essa cultura, que impulsionou sua crise e a possibilidade de diferentes formas de exercê-la.

Por liquidez, Bauman (2001) diz que é tudo aquilo que muda e se altera em virtude de uma determinada pressão. $\mathrm{O}$ autor discorre sobre a mutabilidade dos sentimentos e ações das pessoas em prol do seu próprio bem-estar. Os princípios e valores, outrora sólidos, hoje são fluidos e totalmente inconstantes, se ajustam de acordo com a circunstância. O mundo líquido é efêmero, passageiro e desenraizado. Não há solidez e tudo o que é agora, pode não o ser mais daqui a pouco. Não obstante a mutabilidade de ideias e paradigmas, a sociedade caminha para algum lugar. A questão é: que lugar é esse?

O período pós-moderno pode ser representado pelo conceito de liberdade. As lutas e discussões presentes nesta era culminam, em geral, na emancipação dos padrões sóciohistoricamente estabelecidos. À luz deste trabalho, pode-se destacar as relações de gênero que,

\section{POLÊM!CA $\mid$ LABORÉ}

Polêmica - Revista Eletrônica da Uerj - Rua São Francisco Xavier, 524, $1^{\circ}$ andar

bloco D, sl.1001 • Tels.: +55 21 2334-4088 / 4087 • http://www.e-publicacoes.uerj.br/index.php/polemica/index http://www.labore.uerj.br • laboreuerj@yahoo.com.br 
como visto anteriormente, foram moldadas de acordo com o modelo patriarcal, no qual o homem exercia toda e qualquer função social importante e a mulher cuidava da casa, filhos e era totalmente submissa ao seu marido.

Bonácio (2012) aponta que as diversas mudanças ocorridas só foram possíveis na pósmodernidade. Como já dito, uma importante característica deste período é a fragilização e a quebra do que no passado era uma certeza universal. Isso leva a uma possibilidade de mudança social que afeta diretamente o modo de vida e de ser da sociedade. Hoje, a mobilidade é uma característica marcante: das relações, dos planos, dos sonhos e de tudo com que o ser humano necessite lidar. Tal como o conceito de liquidez, assim tem sido a vida da sociedade pósmoderna.

O combate entre indivíduo e cidadão, citado por Bauman (2001), mostra o quão afetada é a presente sociedade pelo processo de individuação. Ele aponta que "a individualização chegou para ficar" (Ibid., p. 47), e diz ainda que "[...] a opção de escapar à individualização e de se recusar a participar do jogo da individualização está decididamente fora da jogada" (Ibid., p. 43).

Ser cidadão significa ter gozo no coletivo, não apenas estar inserido na sociedade, mas tendo prazer em fazer parte dela. Em contraponto, o indivíduo é aquele que se mostra mais egoísta, não demonstrando apreço pelo o que tange o social, já que entende que investir no que é comum a outros é se privar de maiores resultados para si (BAUMAN, 2001).

Este processo de individuação contribui para que problemas que sejam inerentes à sociedade sejam tratados de forma dúbia, a fim de, possivelmente, atender aos interesses de uma parcela de indivíduos. Bauman (2001) aponta a lógica higienista no pensamento destes que defendem, por exemplo, apenas a retirada do convívio social de pessoas em conflito com a lei. Desta forma, todos os problemas sociais envolvidos em tal questão, como desemprego, educação precária, dificuldade de acesso a saúde, entre outros, são ignorados. A partir destas situações, emerge a marginalização de tais pessoas em detrimento da busca de resoluções para os problemas que envolvem o meio social.

A sociedade é imersa em uma cultura e é esta quem irá ditar o que é certo e errado, o que pode ou não pode, o que é considerado bonito e o que é visto como feio. Será ela que ditará as regras de convívio, comportamento e, inclusive, dos papéis de gênero. O termo cultura é definido por Bauman (2013, p. 12) como "um instrumento de navegação para orientar a evolução social rumo a uma condição humana universal". Contudo, tal conceito tem funcionado

\section{POLÊM!CA $\mid$ LABORÊ}

Polêmica - Revista Eletrônica da Uerj - Rua São Francisco Xavier, 524, $1^{\circ}$ andar bloco D, sl.1001 • Tels.: +55 21 2334-4088 / 4087 • http://www.e-publicacoes.uerj.br/index.php/polemica/index http://www.labore.uerj.br • laboreuerj@yahoo.com.br 
como um preservador do que outrora fora construído e chamado de cultura.

Com o advento do pós-modernismo, a cultura deixa de ser uma ditadora de regras para se tornar uma propiciadora de oportunidades. Agora, a cultura permite o sujeito ser quem ele queira ser. Contudo, tal liberdade permite o surgimento de novas questões no que se refere ao convívio social.

O tempo atual que Bauman (2013) chama de líquido-moderno traz consigo, porém, um peso de exclusão e segregação, pois não há tolerância. O que incomoda é pura e simplesmente extirpado. Essa é mais uma amostra do que é a individuação: não existe espaço para compartilhar queixas e aflições, há apenas uma busca pelo prazer individual e próprio. E é justamente por isso que a liquidez dita por Bauman (2001) se encaixa perfeitamente para definir o tempo em que vivemos. Ao menor sinal de pressão, as coisas se reorganizam de forma a gerar uma ruptura nas relações. O outro é descartado quando deixa de atender uma necessidade que esse indivíduo tenha.

A liberdade que o tempo pós-moderno trouxe torna-se um problema que se desdobra no que Bauman (1998) chama de o mal-estar da pós-modernidade. Vivemos em uma época de consumo, o que inclui objetos e pessoas. A possibilidade de se relacionar com quem se queira, e também de ter tudo o que se consiga, contribui para que este sujeito se envolva no processo de individuação, já que passa a pensar apenas em sua própria satisfação. Este fenômeno pode ser explicado pelo capitalismo, uma vez que ele promove a necessidade de adequação social, de consumir, de trocar o que está ultrapassado e que não atende mais suas demandas, visto que a todo instante é lançado um produto novo que vem para suprir a carência do anterior. Essa lógica de descarte e substituição alcançou as relações, por isso, como defende Bonácio (2012), percebem-se nos dias atuais as misérias, crises e incertezas.

Segundo Maciel Junior e Costa (2016, p. 106), "O consumo é uma maneira de se organizar da sociedade atual onde objetos passam a ter mais valores que pessoas e até pessoas se tornam objeto". Consome-se de tudo, de objetos a pessoas e relações. Assim, a vida se torna efêmera, volátil, líquida.

Pensar a masculinidade dentro dessa liquidez, remete ao que Bauman $(2001,1998)$ propõe como sendo uma possível solução para esse mal-estar: "Quem sabe não seria um remédio manter-se, como no passado, ombro a ombro e marchar unidos?” (BAUMAN, 2001, p. 48). Uma vez que vivemos um momento de desconstrução e de ruptura do patriarcado e sua hegemonia, unir-se em prol da pluralidade de formas de ser homem pode ser a maneira que os

\section{POLÊM!CA}

Polêmica - Revista Eletrônica da Uerj - Rua São Francisco Xavier, 524, $1^{\circ}$ andar

bloco D, sl.1001 • Tels.: +55 21 2334-4088 / 4087 • http://www.e-publicacoes.uerj.br/index.php/polemica/index http://www.labore.uerj.br • laboreuerj@yahoo.com.br 
sujeitos do sexo masculino encontrem para enfrentar e vencer este processo.

Lipovetsky (2004) diz que os indivíduos podem ou não assumir a responsabilidade pelo controle de si ou de serem levados pela massa. Isso significa dizer que o homem tem a escolha de sustentar quem ele é ou de se adequar ao que é socialmente imposto. Temos visto uma mudança concernente aos pensamentos tradicionais, porém, é um processo demorado e muitas das vezes penoso e angustiante.

O autor coloca que o tempo em que vivemos é cercado de hiper, tudo é muito grande e vasto. Ele correlaciona com a individualidade, explicando que:

[...] o hiperindividualismo coincide não apenas com a internalização do modelo do homo economicus que persegue a maximização de seus ganhos na maioria das esferas da vida (escola, sexualidade, procriação, religião, política, sindicalismo), mas também com a desestruturação de antigas formas de regulação social dos comportamentos [...] (LIPOVETSKY, 2004, p. 56).

Para o autor, já não se vive o 'pós' e sim o 'hiper' e, portanto, o que acontece é uma hipermudança (LIPOVETSKY, 2004). É preciso evoluir, mudar e não há espaço para o contrário, pois, se não o fizer, a evolução irá ultrapassar esse sujeito, deixando-o para trás.

Diante do corrente cenário, é possível pensar sobre as redefinições das identidades sociais. Há um processo de construção, mas também de reconstrução, dos pensamentos políticos, que se tornam mais diversificados e menos rígidos, sem o compromisso de perpetuação de uma cultura. Seu sentido inicial era de nortear o avanço e o desenvolvimento, porém, como destaca Bauman (2013, p. 17), “em tempos líquidos-modernos, a cultura [...] é modelada para se ajustar à liberdade individual de escolha", o que expõe a individuação como base dos costumes da sociedade atual.

Cada vez mais a cultura é discutida e moldada dia após dia. Uma amostra disso é a internet, meio pelo qual grande parte das discussões presentes na atualidade são iniciadas e fomentadas. Maciel Junior e Costa (2016, p. 104) trazem uma reflexão sobre o papel da internet no mundo atual e a colocam como um "retrato virtual do que o mundo atual é". Vemos nas redes sociais os mais variados tipos de manifestações sociais. Nessas plataformas, todos se mostram e defendem suas ideias, pontos de vista e verdades, possibilitando, assim, muitas discussões acerca dos mais diversos temas e, desse modo, influenciando a cultura de uma forma geral.

A internet hoje, através das redes sociais e dos sites de notícias ou blogs, dentre outros,

\section{POLÊM!CA $\mid$ LABORE}

Polêmica - Revista Eletrônica da Uerj - Rua São Francisco Xavier, 524, $1^{\circ}$ andar bloco D, sl.1001 • Tels.: +55 21 2334-4088 / 4087 • http://www.e-publicacoes.uerj.br/index.php/polemica/index http://www.labore.uerj.br • laboreuerj@yahoo.com.br 
é um grande instrumento de formação de opinião de seus usuários. O sujeito que dela faz uso pode saber de fatos que estão acontecendo em qualquer lugar do mundo ou conversar com pessoas de qualquer outro país, em tempo real. Houve um avanço considerável na comunicação da sociedade com o advento da rede. No entanto, mesmo com o encurtamento das distâncias e com o acesso à informação, as relações estão se mostrando cada vez mais frias e as opiniões cada vez mais vazias de consistência.

Para Dias (2005), devido a uma moral empobrecida, temos uma crise de valores e de moralidade. Ao mesmo tempo em que este sujeito se sente livre para fazer as escolhas que bem quiser e viver da forma que mais lhe convém, existe a preocupação se é de fato uma boa opção levar a vida da forma escolhida. Diante dessa situação, a autora acrescenta que existe uma inquietude sobre reconstruir a tradição ao enfrentar as diversas demandas da sociedade (DIAS, 2005). Ainda assim, frente às várias possibilidades que a vida pós-moderna traz, cada um escolhe o caminho com que mais se identifica, moldando-se ao que mais lhe toca e acompanhando o progresso que é melhor para si. É disto que se trata a individuação presente nesta época.

Um contraponto ao pensamento pós-moderno seria a contribuição de Sartre (1970) acerca da responsabilidade do homem frente aos outros. Para o autor, quando um sujeito decide se tornar um indivíduo, ele está mostrando para o mundo que esta é a melhor forma de ser, e por conseguinte, ele tem responsabilidade para com todos (SARTRE, 1970). Percebemos, então, que a tão buscada liberdade na era pós-moderna se torna um incômodo para estes sujeitos. Eles são livres do outro, mas sua liberdade se dá no outro, o que implica dizer que ainda assim estão vinculados um ao outro.

A pós-modernidade é uma era carregada de dilemas, sendo que uns ajudam na transformação e libertação, enquanto outros trazem mais dúvidas e geram crises. Entende-se que dilemas, cultura, relações, subjetividade, intersubjetividade etc. são elementos constitutivos e de manutenção da identidade de todos os sujeitos contemporâneos.

\section{A identidade do homem pós-moderno}

As mudanças no mundo têm impactado subjetivamente a identidade das pessoas. Tais impactos se mostram presentes em todas as áreas da vida, inclusive em como se dão suas relações sociais. Todo sujeito está submetido ao meio social, portanto, todos estão vinculados de alguma forma aos outros seres viventes e essa associação ocorre de diversas formas. No

\section{POLÊM!CA $\mid$ LABORÊ}

Polêmica - Revista Eletrônica da Uerj - Rua São Francisco Xavier, 524, $1^{\circ}$ andar

bloco D, sl.1001 • Tels.: +55 21 2334-4088 / 4087 • http://www.e-publicacoes.uerj.br/index.php/polemica/index

http://www.labore.uerj.br • laboreuerj@yahoo.com.br 
tocante deste artigo, falamos sobre o masculino e as suas possibilidades de representação.

Siqueira (1997) articula sobre a constituição da identidade de gênero e postula que esta se dá pelas significações construídas a partir da família de origem, classe social e da inserção social baseada no tempo e no espaço. Estas pautas sozinhas não definem a identidade de alguém, mas toda a relação existente entre elas, cada sujeito envolvido, suas inter-relações, a subjetividade de cada um e, por conseguinte, a intersubjetividade destas relações resulta em uma internalização de significados para esse sujeito.

Foi abordado anteriormente sobre como se davam as relações dos homens com os outros e entre esses e as mulheres, uma relação de total dominação. Bourdieu (2002) corrobora com esse pensamento quando comenta sobre o gozo masculino e aponta as características de ativo e passivo, que podem ser entendidas como masculino e feminino, respectivamente.

A sociedade como um todo é fundamentada nessa divisão dos sexos, cabendo ao masculino representar a força, atividade e dominação, enquanto o feminino expressa a fragilidade, passividade e subordinação. Isto é perceptível em todos os âmbitos da sociedade, inclusive no discurso corrente. Perguntas do tipo ‘quem é a mulher/homem da relação' feitas a um casal homossexual demonstram o quanto esse conceito é enraizado.

Ao se estudar sobre as relações de gênero, é natural que se discuta também o machismo. Ele é um reflexo da cultura patriarcal que por muito tempo norteou a sociedade, e sendo considerado um de seus elementos estruturais, foi tão assimilado que traços de machismo são constantemente observados.

Bauman (2001) chama a era atual de pós-moderna, enquanto Lipovetsky (2009) a considera hipermoderna. Porém, ambos os autores convergem no que se refere ao processo de individuação presente neste tempo em que vivemos. A partir desses conceitos e da temática proposta a este trabalho, surgem alguns questionamentos: será possível romper com os dogmas da sociedade patriarcal? Será possível o homem assim o ser, independente de padrões preestabelecidos? O que é ser homem? Machismo e masculinidade se opõem?

O sexo masculino sempre foi o dominador; era o homem quem comandava, quem definia o certo e o errado, o justo e o injusto e a ninguém mais, se não outro homem, caberia julgar ou questionar tais decisões. Essa postura autoritária e dominante é explicada pelo conceito de masculinidade hegemônica, já apresentado aqui.

Segundo Bourdieu (2002), a dominação masculina é tão ampla que tudo que se refere ao homem dispensa justificativa. Ela é naturalizada e livre de imposição da força. Para o autor,

\section{POLÊM!CA LABORÉ}

Polêmica - Revista Eletrônica da Uerj - Rua São Francisco Xavier, 524, $1^{\circ}$ andar

bloco D, sl.1001 • Tels.: +55 21 2334-4088 / 4087 • http://www.e-publicacoes.uerj.br/index.php/polemica/index http://www.labore.uerj.br • laboreuerj@yahoo.com.br 
o arranjo social ratifica as bases em que a dominação se apoia, como na divisão do trabalho e atividades entre os sexos. As relações de gênero se explicam pela imposição de significados a um corpo sexuado.

Assim como postula Beauvoir (2009), o homem goza de ser tido como animal, enquanto a mulher, chamada de fêmea, é tida como um ser submisso e que deve ser dominado. A autora faz uma analogia com o processo de fecundação de um óvulo por um espermatozoide como uma crítica a como os homens veem e se relacionam com as mulheres. Ela defende que o óvulo devora e emascula o espermatozoide, o que nos leva a uma reflexão de que o homem tem medo de ser dominado pela mulher e por isso tomou a dianteira em fazê-lo (BEAUVOIR, 2009). Para alguém dominar algo ou alguém, é preciso se impor, e esta imposição pode se dar de diversas formas, dentre elas, pela força, pelo controle emocional, financeiro etc.

A sociedade em que vivemos hoje se fundamentou no patriarcado, cujo modo de funcionamento configurava o homem com as rédeas da sociedade para si e responsável em definir os papéis a serem exercidos. Cabia a mulher o cuidado com a casa e os filhos, sendo inconcebível a ideia de ela trabalhar fora e/ou ter qualquer outra ocupação social. Dessa forma, o poder continuaria nas mãos do homem e ele continuaria sendo o ser superior que sempre disse ser.

Bourdieu (2002) comenta a diferença anatômica dos sexos e nos mostra que homem e mulher são vistos, respectivamente, como uma variação superior e inferior da mesma fisiologia. De modo similar, Botton (2007) nos fala sobre a masculinidade tida como naturalista, onde a posse do pênis é o que determina essa superioridade. $\mathrm{O}$ autor aponta ainda que esta diferença “[...] era fruto de uma estrutura natural inquestionável” (BOTTON, 2007, p. 110).

Beauvoir (2009) faz um contraponto a essa visão sexual-biológica da separação dos sexos, fundamentando-se na diversidade da própria natureza. A reprodução era um dos pilares que sustentavam a hegemonia masculina, afinal, era o homem quem depositaria o seu espermatozoide, ocasionando, assim, a fecundação do óvulo e se iniciando o processo de geração de uma nova vida. A autora ressalta que até mesmo sobre a reprodução o homem se coloca como superior, visto que o macho enxerga na fêmea apenas aquela que carrega e alimenta o fruto de sua semente. Nessa visão patriarcal, que é corroborada pelas teorias de Aristóteles e Hipócrates, a força e o vigor necessários à geração de uma vida estão no que eles chamam de esperma forte.

Quando falamos de patriarcado, estamos falando de uma cultura. Não em seu sentido

\section{POLÊM!CA $\mid$ LABORÉ}

Polêmica - Revista Eletrônica da Uerj - Rua São Francisco Xavier, 524, $1^{\circ}$ andar

bloco D, sl.1001 • Tels.: +55 21 2334-4088 / 4087 • http://www.e-publicacoes.uerj.br/index.php/polemica/index http://www.labore.uerj.br • laboreuerj@yahoo.com.br 
original, mas como uma forma de perpetuar um pensamento - nesse caso, a dominação masculina. E com essa dominação originam-se algumas outras culturas, entre elas a do machismo.

Drumont (1980, p. 81) define o machismo como sendo "um sistema de representações simbólicas, que mistifica as relações de exploração, de dominação, de sujeição entre o homem e a mulher". Tem-se no machismo uma das ferramentas do patriarcado para a manutenção da dominação do homem sobre a mulher. Ao se valer de frases como 'mulher não faz isso', 'lugar de mulher é na cozinha', 'isso é coisa para homem', ocorre uma perpetuação da lógica machista.

As crianças, em geral, crescem ouvindo concepções semelhantes às frases supracitadas e internalizam que existem coisas para meninos e coisas para meninas. Evidentemente que não se pode negar tal afirmação como um todo, mas trata-se de uma questão de caráter moral. Biologicamente falando, existem distinções sim e, por conseguinte, haverá 'coisas' de menino e de menina.

Ser homem também significava ser viril, forte e potente e essas características não surtiriam efeito se não houvesse em quem usá-las. A partir daí, vemos a construção do que é o machismo. O homem, para subjugar e dominar a mulher, se utiliza dessas atitudes para se impor e controlá-la de forma que ela não ofereça nenhum risco a sua hegemonia.

É preciso ressaltar que a cultura machista se manteve inabalável por muito tempo devido a essa construção patriarcal que a permeava. Afinal, as próprias mulheres durante muito tempo permaneceram caladas em tais posições, em que foram colocadas pelos mais diversos motivos, sejam de ordem econômica, pelos filhos, pressão social ou a família de origem. Com isso, os homens sentiram-se "donos" de suas mulheres e, de alguma forma, consideravam todas como uma propriedade, a qual poderia ser adquirida ou até mesmo tomada. Diante disso, Machado (1998) ressalta que os homens sempre acharam poder desfrutar das mulheres, ainda que elas dissessem não. Eles se prevaleciam delas por conta de sua posição social e por até então se sentirem e serem vistos como superiores.

Com a quebra dessa submissão e surgimento dos movimentos feministas, as mulheres se contrapuseram ao sistema opressor do patriarcado. Nesse momento histórico surgem diversas questões e, como já dito anteriormente, o homem é questionado sobre o seu papel e como ele se dá.

Nesse momento de reflexão sobre o lugar que ocupa o homem e sobre como é ser do

\section{POLÊM!CA LABORÉ}

Polêmica - Revista Eletrônica da Uerj - Rua São Francisco Xavier, 524, $1^{\circ}$ andar

bloco D, sl.1001 • Tels.: +55 21 2334-4088 / 4087 • http://www.e-publicacoes.uerj.br/index.php/polemica/index

http://www.labore.uerj.br • laboreuerj@yahoo.com.br 
sexo masculino, se inicia a crise da identidade masculina. Em crise, esse homem passa a refletir sobre suas atitudes, pensamentos, na forma com que lida com os outros. É a partir de momentos assim que se propicia o início de uma mudança ou a perpetuação do pensamento vigente até então. A hegemonia masculina ainda impera, mas é vista com outros olhos. É questionada, criticada e busca-se até a sua derrocada, uma vez que ela traz consigo uma série de atitudes, pensamentos e diretrizes consideradas estapafúrdias para os dias pós-modernos.

Segundo Connell e Messerschimidt (2013), a posse e uso da hegemonia se dão por uma minoria dos homens. Porém, ambos autores concordam que ela é normativa e se traduz no que eles chamam ser "a forma mais honrada de ser um homem" (CONNELL; MESSERSCHIMIDT, 2013, p. 245). A estes homens foram atribuídas uma série de outros padrões comportamentais e subjetivos que se desdobraram como sendo o conceito de masculinidade hegemônica e que garantiriam a dominação masculina.

A Psicologia e a Sociologia já falavam sobre a possibilidade de mudança das normas masculinas antes mesmos dos movimentos libertários femininos, de acordo com Connell e Messerschimidt (2013). No decorrer da década de 1970, houve muitas críticas à fundamentação dos comportamentos masculinos e os autores apontam ainda que tais discordâncias possibilitaram "[...] o primeiro movimento de homens antissexistas" (CONNELL; MESSERSCHIMIDT, 2013, p. 243).

Muito embora durante um longo período histórico tenha-se considerado másculo apenas aqueles que detinham as características hegemônicas, com as atuais mudanças de paradigmas, a sociedade passa a entender e aceitar novas formas de ser masculino. Ademais, vale ressaltar a rejeição aos conceitos hegemônicos, uma vez que o machismo começa a sofrer resistência, não obstante ele ainda seja recorrente no meio da sociedade como um todo.

Pensar a ideia de masculinidade, na atualidade, é considerar o conceito hegemônico e vislumbrar um lugar de desconstrução deste. Isso é tonificado por Connell e Messerschimidt (2013, p. 245): “As masculinidades são configurações de práticas que são realizadas na ação social e, dessa forma, podem se diferenciar de acordo com as relações de gênero em um cenário social particular".

Tal como a fluidez proposta por Bauman (1998), as masculinidades assim o são. Cada sujeito a internaliza e vivencia de uma forma, o que não invalida outras. Isso se contrapõe ao estilo clássico de pensar o que é ser homem, em que se deveria seguir os padrões existentes.

Ser homem, na atualidade é uma experiência nova, pois essa quebra de paradigmas tem

\section{POLÊM!CA $\mid$ LABORÉ}

Polêmica - Revista Eletrônica da Uerj - Rua São Francisco Xavier, 524, $1^{\circ}$ andar

bloco D, sl.1001 • Tels.: +55 21 2334-4088 / 4087 • http://www.e-publicacoes.uerj.br/index.php/polemica/index

http://www.labore.uerj.br • laboreuerj@yahoo.com.br 
mostrado a todos que não há apenas uma forma de sê-lo. Além disso, o conceito clássico de ser masculino era andar em sentido oposto ao que é ser feminino, o que nos remete a várias possibilidades de comportamentos e funções, dentre os quais podemos destacar o cuidado com os filhos. Esta tarefa, responsabilidade da mãe de outrora, ou seja, da mulher, agora é também do homem.

Cabe ao homem contemporâneo a mesma responsabilidade da mulher sobre os filhos. Isso implica em trocar fraldas, alimentar, educar, dentre outras atividades inerentes ao cuidado e criação de uma criança. Mas será que a sociedade, de uma forma geral, já se abriu para esta nova perspectiva? Até mesmo as leis vigentes no Brasil possuem referências ao machismo, ainda que de modo não explícito. Para que haja um enfrentamento quanto a isto, ocorrem as emendas e criam-se novas leis a fim de reparar e atualizar possíveis discrepâncias ocasionadas pela mudança da cultura.

\section{O fraldário masculino}

Os costumes sociais tomaram rumos diversos ao longo dos tempos. Conforme ocorre a evolução social, cabe a quem for de direito zelar pela atualização das leis, para que estas amparem as transformações mais recentes e supram as necessidades e interesses da população.

Vivemos em uma época de mudanças, libertação, novidades, desconstrução e reconstrução. Tal como a liquidez de Bauman (2001), a vida em sociedade tem sido muito fluida, o que caracteriza uma necessidade de rever conceitos e pensamentos que norteiam essa convivência. Um belo exemplo é a paternidade, pois a função paterna, enquanto exercida por um homem, tem se revelado de uma nova forma, fugindo aos padrões de outrora.

Visando uma evolução e até uma quebra de paradigma, no que tange ser sempre relacionado à mãe o cuidado de uma criança, a prefeitura de São Paulo decretou a Lei n. 16.736, de $1^{\circ}$ de novembro de 2017, que determina que os shoppings que estão dentro da cidade construam ou adaptem espaços para serem usados por ambos os sexos para a troca de fraldas de crianças (SÃO PAULO, 2017).

Babadobulos (2018) narra em sua matéria situações embaraçosas pelas quais alguns pais já passaram e levanta a questão de como proceder sendo a criança um filho ou filha de um casal homoafetivo. $\mathrm{O}$ autor frisa, ainda, que a troca de fralda não é uma obrigação da mãe, ainda que a esta seja costumeiramente atribuída tal função.

Esta hiperresponsabilização da maternidade é um reflexo do machismo que é instaurado

\section{POLÊM!CA $\mid$ LABORÉ}

Polêmica - Revista Eletrônica da Uerj - Rua São Francisco Xavier, 524, $1^{\circ}$ andar

bloco D, sl.1001 • Tels.: +55 21 2334-4088 / 4087 • http://www.e-publicacoes.uerj.br/index.php/polemica/index

http://www.labore.uerj.br • laboreuerj@yahoo.com.br 
na sociedade. Aqui se retorna ao ponto em que foram definidos os papéis de gênero e que para a mulher coube o cuidado doméstico e dos filhos. Por isso temos, até hoje, essa ideia de que é a mãe quem troca a fralda da criança. $\mathrm{O}$ advento dessa lei é uma vitória para todos aqueles que lutam por condições igualitárias entre os sexos e que defendem que o exercício da paternidade seja tão amplo quanto sempre foi o da maternidade.

A incumbência masculina no cuidado e educação de uma criança é a mesma que a feminina. Daí a importância de se romper com a lógica machista de que tais tarefas são da mãe e o pai ajudará como puder. Justamente pela paridade de responsabilidades, a prática do cuidado é tão somente o cumprimento de um dever.

O deputado Felipe Bornier foi o relator da Comissão de Seguridade Social e Família do Projeto de Lei n. 1.534 de 2015 e justificou seu voto a favor da criação da lei, fazendo esse contraponto de que não é apenas a mulher que cuida dos filhos e que o homem também exerce esse papel (SÃO PAULO, 2018), não podendo ele, assim, ser privado de um local com condições adequadas para a realização da troca de fralda da criança. O deputado aponta, ainda, que a instalação desses fraldários se dá como um diferencial, para atrair clientes, e que inexiste uma lei federal que obrigue a instalação destes em banheiros femininos, mas que é lá que eles são instalados. Portanto, uma melhor saída para resolver as dificuldades que os pais têm para trocar seus filhos é determinar que sejam instalados locais para acesso comum a ambos os sexos e, na impossibilidade, que se instalem nos dois banheiros, a fim de que o homem também tenha a possibilidade de efetuar a troca de fraldas de sua criança.

Moema Gramacho, que foi a deputada e relatora da Comissão de Desenvolvimento Urbano disse, em seu voto a favor da aprovação do Projeto de Lei $n^{\circ} 1.534$ de 2015, que o estatuto da cidade de São Paulo possui políticas para ordenar o total desenvolvimento de funções sociais e, entre tais, ofertar dispositivos urbanos e comunitários que se adequem aos interesses e demandas da população (SÃO PAULO, 2015). Gramacho também acrescenta que a lei deve seguir junto com o avanço das pessoas e a vida em sociedade, visto que nos tempos atuais, a participação dos homens nos cuidados dos filhos tem se generalizado, sendo necessário garantir que todos os direitos dos cidadãos sejam assegurados.

A obrigatoriedade do fraldário em banheiros masculinos nos mostra uma mudança subjetiva do papel do homem - aquele que antes deveria apenas prover e proteger, agora cuida. E, inclusive, luta por ter esse direito assegurado em qualquer local. Afinal, através das reclamações dos homens, diante das mais difíceis situações, chegando a trocar seus filhos no

\section{POLÊM!CA $\mid$ LABORÉ}

Polêmica - Revista Eletrônica da Uerj - Rua São Francisco Xavier, 524, $1^{\circ}$ andar

bloco D, sl.1001 • Tels.: +55 21 2334-4088 / 4087 • http://www.e-publicacoes.uerj.br/index.php/polemica/index http://www.labore.uerj.br • laboreuerj@yahoo.com.br 
chão, é que essa lei foi aprovada (SÃO PAULO, 2015). Agora o homem que mora na cidade de São Paulo sente-se mais tranquilo em sair com seus filhos pequenos, não correndo riscos de não conseguir trocá-los ou fazê-lo em condições críticas. Toda esta situação revela alguns novos comportamentos do homem pós-moderno.

\section{Os novos comportamentos do homem pós-moderno}

Cuidar, lutar pelo direito de cuidar, assumir a paternidade e tudo que ela traz são alguns dos novos comportamentos do homem pós-moderno, mas nem sempre foi assim. A história nos mostra que o homem, em geral, não se preocupava com cuidado e educação dos filhos, afinal, era tarefa da mulher. A reflexão que devemos fazer é que a sociedade ainda vive pautada pela lógica patriarcal e o rompimento com tal preceito tem sido gradual e brando.

Trazendo para a realidade da presente proposição, a presença do fraldário em um banheiro masculino passa algumas mensagens para a sociedade, mas em especial para os homens. Mostra que o homem cuida, ampara, educa, troca, e que toda essa lógica machista e sexista de que tais atividades não pertencem a um suposto campo masculino está equivocada. O fraldário em banheiros masculinos indica para todos que é chegada a hora de uma mudança de paradigmas e postura.

A implementação desta lei, que resulta em um espaço para que o homem também possa executar a função do cuidado, é de uma importância muito grande, pois mostra que os tempos são outros e que é preciso haver mudanças nos pensamentos e ações. Nesse momento, o Estado não pode se furtar da responsabilidade de, através dos recursos legais, incentivar a transformação dos paradigmas. Inclusive, mostra-se necessária a revisão de leis que sustentem esse sexismo e a criação de novas que impulsionem mais mudanças em detrimento da visão patriarcal.

Agora o homem participa, ele é pai de fato. E não perde o seu status de 'macho', muito pelo contrário. Este pensamento ainda não é majoritário, visto toda a densidade do patriarcado, porém, faz parte do pensamento pós-moderno. E como o homem tem se adaptado a ele?

O sujeito que não cumpre com o que se espera hoje de um homem passa a ser questionado e a sua postura, enquanto sujeito do sexo masculino, se torna alvo de críticas. Mas a pós-modernidade originou uma nova era, um tempo em que as verdades estabelecidas até então passaram a ser questionadas e mudanças ocorreram no seio na sociedade, como é o caso das relações de gênero. É assim que o homem, agora, troca as fraldas de seu filho. São mudanças

\section{POLÊM!CA LABORÉ}

Polêmica - Revista Eletrônica da Uerj - Rua São Francisco Xavier, 524, $1^{\circ}$ andar

bloco D, sl.1001 • Tels.: +55 21 2334-4088 / 4087 • http://www.e-publicacoes.uerj.br/index.php/polemica/index http://www.labore.uerj.br • laboreuerj@yahoo.com.br 
que afetam a sociedade como um todo e de forma muito abrangente e que caminham para a naturalidade. Com as desconstruções dos paradigmas patriarcais, a mulher tem conquistado muito mais espaço e o homem tem ganhado novas possibilidades e papéis.

Não é preciso mais se prender aos padrões pré-existentes e nem se reprimir por medo de não aceitação. O homem agora tem a possibilidade de ser livre. Pode ser quem é, seguir o caminho que almeja e o deixa feliz. Neste momento, o sujeito masculino pode exercer suas mais variadas formas de masculinidade.

Segundo Connell e Messerschimidt (2013), masculinidade não é algo rígido que se mostra no corpo ou em traços de personalidade. As masculinidades são arranjos práticos que se dão no social e podem se diferenciar a partir das relações de gênero. A própria hegemonia possui algumas variações sobre como ser homem. Os autores falam de um status regional, apontado que jovens buscam fazer coisas que seus pares consideram como masculinas, a fim de que, assim, sejam também reconhecidos como homem e consigam manter seu prestígio.

Para Ericeira (2008), as conquistas femininas da década de 1990 deram uma grande contribuição para o que hoje entendemos como masculinidades, pois foi a partir delas que o homem passou a compartilhar das tarefas domésticas e da educação dos filhos, o que por si só já mostra uma clara mudança subjetiva do que é ser homem. Até então, essas eram tarefas femininas e ser homem caminhava na direção oposta do que é o feminino.

$\mathrm{O}$ autor propõe algumas questões que nos ajudam a entender melhor todas essas mudanças que vêm ocorrendo com os homens nos últimos tempos. São elas: "Como esses homens assimilaram as conquistas femininas?", "Foram obrigados a reavaliar suas posturas másculas?" (ERICEIRA, 2008, p. 4). Estes questionamentos são oriundos de toda a lógica sociocultural em que estamos imersos.

Tendo o Brasil como exemplo, pode-se constatar uma mudança na cultura local, com a influência de culturas de tantos outros países que levam o homem brasileiro a um processo de transformação de seus paradigmas. Dessa maneira, ele está sim reavaliando suas posturas e tendo um novo olhar sobre toda a ascensão e empoderamento das mulheres. Segundo Bonácio (2012), há um enfraquecimento das sólidas bases da postura tradicional, possibilitando assim essa nova postura.

É justamente pela ascensão da mulher que o homem agora pode mostrar suas mais variadas facetas, pois com os questionamentos feitos por elas, o advento do pensamento pósmoderno e a revolução sexual, agora o homem é livre para ser quem é.

\section{POLÊM!CA $\mid$ LABORÉ}

Polêmica - Revista Eletrônica da Uerj - Rua São Francisco Xavier, 524, $1^{\circ}$ andar bloco D, sl.1001 • Tels.: +55 21 2334-4088 / 4087 • http://www.e-publicacoes.uerj.br/index.php/polemica/index http://www.labore.uerj.br • laboreuerj@yahoo.com.br 
Enquanto no pensamento hegemônico, para ser considerado másculo, era preciso cumprir uma série de exigências e respeitar alguns vários nãos, hoje, o homem pode ser frágil, demonstrar afeto, ser sustentando pela mulher, cuidar dos filhos, da casa, ser homossexual. Entretanto, é válido dizer que esta ainda não é a regra, a sociedade como um todo ainda é heteronormativa.

O que se busca na pós-modernidade não é a extinção do homem 'tradicional', mas sim a reformulação das regras de atuação social. Busca-se o respeito às diferenças, à subjetividade e à individualidade de cada um. Busca-se romper com os conceitos de que o homem pode isso e não pode aquilo, que lugar de mulher é este e não aquele.

As masculinidades são constituídas por aspectos práticos e que se constroem, mudam e se revelam com o passar do tempo. Com isso, percebemos que será a partir destes novos comportamentos e visão da sociedade que se construirá uma nova forma de encarar a subjetividade alheia, incluindo nesta o respeito e o entendimento de que não é necessário haver uma normatividade no que tange as escolhas e modo de ser de cada um.

\section{Considerações finais}

Não se pode pensar em masculinidades sem considerar vários fatores. É preciso sopesar as mulheres, os movimentos feministas, a sociedade patriarcal, a família, as relações de gênero, a subjetividade, as intersubjetividades. Há uma série de elementos que devem ser analisados para que assim haja uma melhor compreensão do tema.

Antes, o homem estava em uma posição de total supremacia, não precisava justificar seus atos e todas suas vontades eram acatadas simplesmente em função do sexo. Porém, com todas essas discussões e lutas, ele cai desse lugar inalcançável. O homem pós-moderno tem percebido que não dá mais para continuar seguindo os preceitos patriarcais, pois são comportamentos que já não são mais tolerados pela sociedade, ainda que haja uma parcela do corpo social que pense diferente e defenda o jeito arcaico de pensar e de ser.

A liquidez a qual estamos submetidos representa uma rápida mudança de cultura e de manutenção desta. Portanto, se faz necessário um esforço de adaptação ao presente a fim de acompanhar o progresso da sociedade e o avanço sociocultural. Corre o risco de ficar para trás todo aquele que não se adequar.

Podemos considerar a quebra da lógica machista como um primeiro passo para romper de vez com o patriarcado. É um trabalho em longo prazo e que demandará muito esforço da

\section{POLÊM!CA $\mid$ LABORÊ}

Polêmica - Revista Eletrônica da Uerj - Rua São Francisco Xavier, 524, $1^{\circ}$ andar bloco D, sl.1001 • Tels.: +55 21 2334-4088 / 4087 • http://www.e-publicacoes.uerj.br/index.php/polemica/index http://www.labore.uerj.br • laboreuerj@yahoo.com.br 
sociedade. O machismo é institucionalizado e reproduzido involuntariamente. O mesmo policiamento aplicado à solidificação dos antigos conceitos deve ser aplicado para a desconstrução de tais pensamentos.

Embora se viva um tempo de excesso, de urgência, é preciso ter calma e discernimento para que as coisas se reorganizem de uma melhor forma. Não se pode confundir zelo com displicência. Porém, não se pode exigir uma mudança instantânea da sociedade. Tal como foi o processo de construção da cultura que rege a sociedade hoje, será o de desconstrução e reconstrução dela.

Um ponto importante a ser revisto pela sociedade, de uma forma geral, é o que se refere a indivíduos e cidadãos. Ainda que estejamos mergulhados em uma era individualista, voltar atrás e rever este ponto pode ser de grande valia para a sociedade como um todo. Afinal, não há como fugir do fato de que todo ser humano está inserido no social.

Sendo assim, vivendo no tempo em que vivemos, onde quase tudo é efêmero e pouco valorizado, unir-se pode ser uma boa ideia. Afinal, a separação só tende a enfraquecer. E no que concerne à temática proposta neste trabalho, o homem tem sido o seu principal inimigo. No momento em que um homem reprisa ideias e falas machistas, ele está perpetuando a suposta dívida que os homens têm com seus pares.

Por dívida entende-se toda uma construção moral e subjetiva da identidade masculina. Enquanto houver essa obrigação, o homem vai crescer tendo como meta ser o popularmente chamado 'macho alfa'. Em outras palavras, seria aquele que detém as características hegemônicas patriarcais bem afloradas.

Todavia, com a união desses sujeitos é possível 'perdoar' esta dívida e, assim, permitir que cada homem exerça a sua masculinidade da forma que ele sinta e perceba que deva ser. Não haverá mais espaço para receios, medos e nada que de alguma forma possa desabonar a condição masculina pela falta ou presença de alguma determinada característica. Desta forma, desconstrói-se a imagem de que para ser homem é preciso ser rude, agressivo e dominador. Entende-se que o processo de construção da identidade masculina é dotado de diversos fatores e que estes estão passíveis de mudanças culturais constantes, de forma que a todo instante a formulação de tal identidade poderá sofrer mudanças. Por homem hoje se entende todo sujeito que se identifica com o gênero masculino, o que mostra mais uma forma de ser homem. Desconstrói-se a imagem popular que ainda é muito latente na sociedade de que só é homem quem é biologicamente designado.

\section{POLÊM!CA $\mid$ LABORÊ}

Polêmica - Revista Eletrônica da Uerj - Rua São Francisco Xavier, 524, $1^{\circ}$ andar bloco D, sl.1001 • Tels.: +55 21 2334-4088 / 4087 • http://www.e-publicacoes.uerj.br/index.php/polemica/index http://www.labore.uerj.br • laboreuerj@yahoo.com.br 
A sociedade pós-moderna está de alguma forma se readaptando, assim como os líquidos, às pressões e situações que se impõem como dificultosas e exigem certa reorganização. Não se pode dizer que são mudanças permanentes, pois seria até uma controvérsia a tudo que já foi apresentado. Contudo, ruma-se para o que originalmente deveria nortear a cultura, que é a condição humana plena.

Sobre a temática da masculinidade, ainda há muito a ser estudado e debatido. Cabe a tantos outros professores, pesquisadores e interessados pelo tema, que perseverem na discussão, a fim de que a informação que tem o poder de transformar e ressignificar possa alcançar tantos quantos possíveis, sejam homens ou mulheres, pois, somente assim, será possível construir identidades masculinas livres de preconceitos.

\section{Referências}

ABREU, R. L. M. Masculinidades: Posicionamentos dos homens nas relações conjugais. 2013. 124f. Dissertação (Mestrado em Psicossociologia de Comunidades e Ecologia Social) - Programa de Estudos Interdisciplinares de Comunidades e Ecologia Social, Universidade Federal do Rio de Janeiro, Rio de Janeiro, 2013.

BABADOBULOS, T. Agora é lei! Shoppings de SP devem ter fraldário também em banheiros masculinos. Revista Crescer, São Paulo, 2 ago. 2018. Disponível em: https://revistacrescer.globo.com/Voce-precisasaber/noticia/2018/08/agora-e-lei-shoppings-de-sp-devem-ter-fraldario-tambem-em-banheiros-masculinos.html. Acesso em: 18 out. 2018.

BAUMAN, Z. A cultura no mundo líquido moderno. Rio de Janeiro: Zahar, 2013.

BAUMAN, Z. Modernidade Líquida. Rio de Janeiro: Zahar, 2001.

BAUMAN, Z. O mal-estar da pós-modernidade. Rio de Janeiro: Zahar, 1998.

BEAUVOIR, S. O segundo sexo. Rio de Janeiro: Nova Fronteira, 2009.

BONÁCIO, D. Representações da masculinidade em crise: legados pós-modernos. In: TASSO, I.; NAVARRO, P. (Org.). Produção de identidades e processos de subjetivação em práticas discursivas. Maringá: EDUEM, 2012. p. 231-258.

BOTTON, F. B. As masculinidades em questão: Uma perspectiva de construção teórica. Revista Vernáculo, Paraná, n. 19-20, p. 109-120, 2007.

BOURDIEU, P. A dominação masculina. Rio de Janeiro: Bertrand Brasil, 2002.

CONNELL, R. W.; MESSERSCHIMIDT, J. W. Masculinidade hegemônica: repensando o conceito. Estudos Feministas, Florianópolis, v. 21, n. 1, p. 241-282, 2013.

DIAS, R. C. P. Resenha: Modernidade e identidade. Psicologia \& Sociedade, Belo Horizonte, v. 17, n. 3, p. 80$81,2005$.

DRUMONT, M. P. Elementos para uma análise do machismo. Perspectivas, São Paulo, n. 3, p. 81-85, 1980.

\section{POLÊM!CA $\mid$ LABORE}

Polêmica - Revista Eletrônica da Uerj - Rua São Francisco Xavier, 524, $1^{\circ}$ andar

bloco D, sl.1001 • Tels.: +55 21 2334-4088 / 4087 • http://www.e-publicacoes.uerj.br/index.php/polemica/index http://www.labore.uerj.br • laboreuerj@yahoo.com.br 
ERICEIRA, R. C. S. O homem na pós-modernidade: reflexões sobre as identidades masculinas em São LuísMA. Psicol. Am. Lat., México, n. 13, jul. 2008.

LAGO, M. C. S.; WOLFF, C. S. Masculinidades, diferenças e hegemonias. Estudos Feministas, Florianópolis, v. 21, n. 1, p. 233-240, 2013.

LIPOVETSKY, G. O império do efêmero: a moda e seu destino nas sociedades. São Paulo: Companhia das Letras, 2009.

LIPOVETSKY, G. Os tempos hipermodernos. São Paulo: Editora Bacarolla, 2004.

MACHADO, B. F. Estudos de masculinidades: a crise masculina, a masculinidade hegemônica e a paternidade em Onde estão os ovos? de Fabrício Carpinejar. Mosaico, v. 7, n. 11, p. 49-63, 2016.

MACHADO, L. Z. Masculinidade, sexualidade e estupro: As construções da virilidade. Cadernos Pagu, Brasília, n. 11, p. 231-273, 1998.

MACIEL JUNIOR, G. C.; COSTA, M. H. O modo de ser-no-mundo virtual: o dasein e o facebook. Polêm!ca, Rio de Janeiro, v. 16, n. 1, p. 95-121, jan. 2016.

RABELO, A.O. Contribuições dos Estudos de Género às Investigações que Enfocam a Masculinidade. Ex aequo, Vila Franca de Xira, n. 21, p. 161-176, 2010.

SÃO PAULO. Câmara dos Deputados. Projeto de Lei n. 1.534, de 2015. Determina a instalação de fraldários nos banheiros de uso público masculinos. Comissão de Desenvolvimento Urbano. Autor: Deputado Chico D’Angelo. Relatora: Deputada Moema Gramacho. 2015. Disponível em:

https://www.camara.leg.br/proposicoesWeb/prop_mostrarintegra;jsessionid=node01 mqxvyunddmd112halg8qyf 2x329959991.node0?codteor=1405206\&filename=Tramitacao-PL+1534/2015. Acesso em: 22 ago. 2021.

SÃO PAULO. Câmara dos Deputados. Projeto de Lei n. 1.534, de 2015. Determina a instalação de fraldários nos banheiros de uso público masculinos. Comissão de Seguridade Social e Família. Autor: Deputado Chico D’Angelo. Relator: Deputado Felipe Bornier. 2018. Disponível em:

https://www.camara.leg.br/proposicoesWeb/prop_mostrarintegra?codteor=1667978\&filename $=\mathrm{PRL}+1+\mathrm{CSSF}+$ $\% 3 \mathrm{D} \% 3 \mathrm{E}+\mathrm{PL}+1534 / 2015$. Acesso em: 22 ago. 2021.

SÃO PAULO. Prefeitura de São Paulo. Lei n. 16.736, de 2017. Dispõe sobre a obrigatoriedade da construção ou adaptação de fraldários acessíveis aos frequentadores de shopping centers e estabelecimentos similares, e dá outras providências. Disponível em: http://legislacao.prefeitura.sp.gov.br/leis/lei-16736-de-1-de-novembro-de2017. Acesso em: 16 set. 2021.

SARTRE, J. P. O existencialismo é um humanismo. Tradução de Rita Correia Guedes. Paris: Les Éditions Nagel, 1970.

SIQUEIRA, M. J. T. A Constituição da Identidade Masculina: Alguns pontos para discussão. Psicol. USP, São Paulo, v. 8, n. 1, p. 113-130, 1997.

Recebido em: 11/03/2021.

Aceito em: 16/09/2021.

\section{POLÊM!CA $\mid$ LABORE}

Polêmica - Revista Eletrônica da Uerj - Rua São Francisco Xavier, 524, $1^{\circ}$ andar bloco D, sl.1001 • Tels.: +55 21 2334-4088 / 4087 • http://www.e-publicacoes.uerj.br/index.php/polemica/index http://www.labore.uerj.br • laboreuerj@yahoo.com.br 